\title{
Monitoring the Environmental Changes of Mariout Lake during the Last Four Decades Using Remote Sensing and GIS Techniques
}

\begin{abstract}
Multi-dates satellite images have been used in this study to detect the trends of environmental changes in Mariut Lake, particularly for the main two lake ecosystems; water, and vegetation. The study focuses on the aquatic vegetation type and water area of Mariout Lake during the past four decades (from 1972 to 2016). The results reported in this research represent the way in which ecosystem degradation processes, affecting Lake Mariout, are increased due to external factors (human activities) of drying and reclaiming some areas to estimate the consequential effects on the lake. A combination of LandSat-1(MSS), LandSat-5 (TM), LandSat-7 (ETM+), SPOT-1, SPOT-4, SPOT-5, Rapid Eye, and Sentinel-2 Satellite data were used to analyze temporal changes in the Lake ecosystem. Different image processing techniques were under taken such as: on screen digitizing to delineate the lake boundary, the Normalized Difference Water Index (NDWI) makes use of reflected near-infrared radiation and visible green light to enhance the presence of such features while eliminating the presence of soil and terrestrial vegetation features, and change detection to ascertain the changes of water and vegetation features within last Four decades interval. The results of analysis indicate that Mariut Lake has been subjected to various physical and biological changes mainly due to the different human activities that have serious impacts on its quality and a subsequent deterioration in its ecological parameters.
\end{abstract}

Keywords: satellite, vegetation, regeneration, kind, quality, distribution
Volume 2 Issue 5 - 2017

Sameh B El Kafrawy,' Noha S Donia, ${ }^{2}$ Amany

Morsi Mohamed'

'National Authority for Remote Sensing and Space Sciences (NARSS), Egypt

${ }^{2}$ Institute of Environmental Studies and researches (ASU), Egypt

Correspondence: Sameh B El Kafrawy, National Authority for Remote Sensing and Space Sciences (NARSS), Egypt, Emailsameh@narss.sci.eg, s_elkafrawy@yahoo.com

Received: June 04, 2017 | Published: July 28, 2017
Abbreviations: GLCF, global land cover facilities; NDWI, the normalized difference water index; USGS, United states geological survey

\section{Introduction}

Remotely sensed data can be used as a tool to detect, monitor and evaluate changes in ecosystems to develop management strategies for ecosystem resources, Satellite and airborne systems monitoring system for large scale earth surface viewing and provide a usable data base for change detection studies.

Remote sensing data can be used to expanse temporal and spatial scales ranging from local systems to overall global systems. Donia ${ }^{1}$ noted that common types of detectable change in remotely sensed data are associated with the clearing of natural vegetation, increased cultivation, urban expansion, changing surface water levels, post- fire vegetation regeneration, and soil disturbances resulting from mining, landslides and animal overgrazing. The use of satellite data is very suitable in inventorying the kind, quality, distribution, and condition of natural vegetation found on range and forest lands. ${ }^{2}$ The basic requirement for remote sensing environmental monitoring is the availability of different dates of imagery upon which the same area of land can be observed. Monitoring global, regional and local areas can be performed by restricting the analysis to a single sensor series or by using different satellite data. New multi-source satellites are creating data at higher spatial and temporal resolution than have been collected at any other time on earth. The selection of low cloud cover imagery with careful attention to selecting the dates through the year(s) is very important. In this study, observations made by LandSat-1(MSS), LandSat-5 (TM), LandSat-7 (ETM+), SPOT-1, SPOT-4, SPOT-5, Rapid Eye, and Sentinel-2 satellite data. Lake Mari out is a highly dynamic aquatic system that has undergone considerable physical, chemical and biological changes during last four decades. The lake has been gradually transformed from a largely marine to eutrophic water system, due to continuous drying processes for cultivation purpose and human settlement and pollution with different kinds of water discharge into the lake. Many studies have been conducted to describe the ecology of the lake; however, none of the previous studies has been implemented to protect the continuous damage and restoration of Lake Mari out. The objectives of this research were to use remote sensing and GIS techniques to measure the spatial distribution of aquatic and marginal vegetation and open water areas in Mariout Lake during the last four decades. The results of analysis indicated that Lake lost $11.19 \mathrm{~km}^{2}$ of its overall size; NDWI indicated that change in Aquatic Vegetation for all basins increased by $27.68 \mathrm{~km}^{2}$, and the changes in water for all basins decreased by $38.67 \mathrm{~km}^{2}$. The change detection results showed changed area that converted into aquatic vegetation, unchanged area that still water, and lost area that no longer exists. These results that due to different anthropogenic activities such as drying and reclaiming some areas that have dangerous impacts on its quality and a subsequent deterioration in its ecological parameters.

\section{The study area}

The present Lake Mari out represents a small portion of a larger lake that was known during the Roman era by Lake Mariutus. Lake Mariout is a small shallow basin located in the southwestern part of Alexandria; it is $25 \mathrm{~km}$ long and about $10 \mathrm{~km}$ width as shown in Figure 1. It is the smallest, and the most polluted lake among the northern lakes of Egypt and it is the only one that does not have a natural connection to the Mediterranean Sea. The excess water is constantly discharged into the sea through El-Max Pumping Station. ${ }^{3}$ The lake serves as a drainage basin for the adjacent cultivated lands; ${ }^{4}$ therefore, 
the main basin of the lake has been suffering from high pollution levels. Water quality was not suitable for aquaculture activities because the basin receives daily about $200,000-300,000 \mathrm{~m}^{3} /$ day of sewage and $400,000 \mathrm{~m}^{3} /$ day of agricultural waste water mixed with sewage. In addition discharging about $25,000-35,000 \mathrm{~m}^{3} /$ day of raw sewage and some industrial waste water into the lake. ${ }^{5,6}$ Throughout the last four decades, the lake has been subjected to man-made changes in its morphometric features as its area has been reduced.

\section{Materials and methods}

\section{Satellite data}

The achieved images were downloaded. Landsat (MSS, TM, ETM+, ETM), and Sentinel-2 given by Global land cover facilities (GLCF) and United States Geological Survey (USGS) were used. All bands data were available, including the metadata files. The SPOT-1, SPOT-4, SPOT-5, and Rapid eye images have been given by NARSS. Satellite data required accomplishing the objectives of remote sensing activities and consequently achieving the study objectives as shown Table 1 that summarizes the Characteristics of satellite images, which were used for Mariout Lake, were integrated in a geographic information system (GIS).

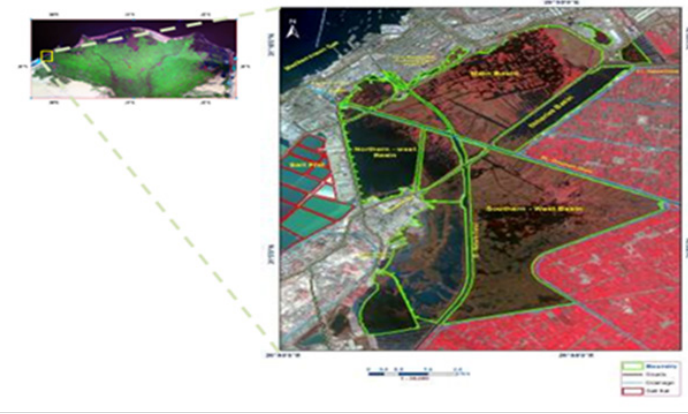

Figure I Study area (Rapid eye 24/0I/20I5, spatial resolution: 5m).

\section{Image processing}

Calculating total area: It determines changed area for each basin. It was found that considerable changes have taken place, by digitizing using ARCMAP 10.2.2 which is effective for area monitoring as shown in Figure 2.

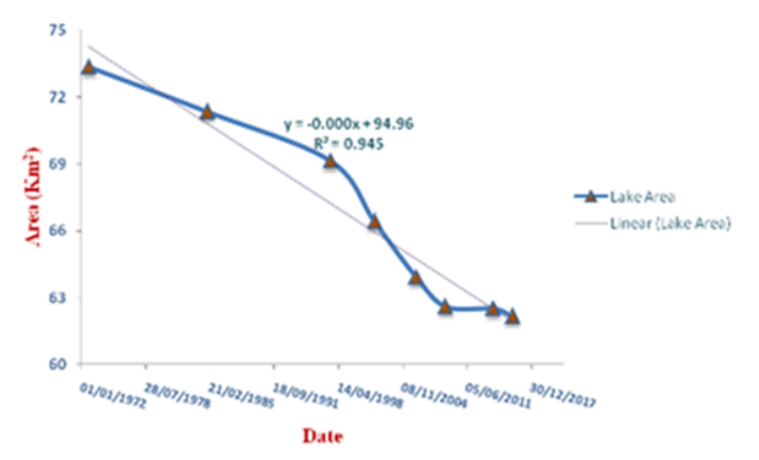

Figure 2 Calculated lake area during 1972 to 2016 .

NDWI: The Normalized Difference Water Index (NDWI) was first proposed by McFeeters in 1996 to detect surface water in wetland environments and to allow for the measurement of surface water extent, ${ }^{7}$ and it produces a single grayscale image, where water is bright. Although the index was created for use with different images data, it has been successfully used with other sensor systems in applications where the measurement of the extent of open water is needed ${ }^{8}$ (USGS, 2016). The NDWI is calculated using Equation (1):

$$
\mathrm{NDWI}=(\text { GREEN }-\mathrm{NIR}) /(\text { GREEN }+\mathrm{NIR})
$$

Where: green is the TOA green light reflectance band and NIR is the TOA near-infrared (NIR) reflectance band. McFeeters ${ }^{7}$ asserted that values of NDWI greater than zero are assumed to represent water surfaces, while values less than, or equal, to zero are assumed to be non-water surfaces. Values of NDWI were calculated from the Satellite images using Equation (1) in the Raster Calculator tool in the Spatial Analyst extension in ARCGIS 10.2.2, then isolate water pixels. ${ }^{9}$

Change-detection technique: This technique automatically discriminates the changed and unchanged pixels of the difference image.

There are three main methods of change detection:

a. Image subtraction method;

b. Image ratio method;

c. The method of change detection after classification.

After the completion of NDWI classification of all satellite images from (1972-2016) and calculation of the water and vegetation area, the image subtraction method was performed to calculate the decrease, unchanged, and losses area.

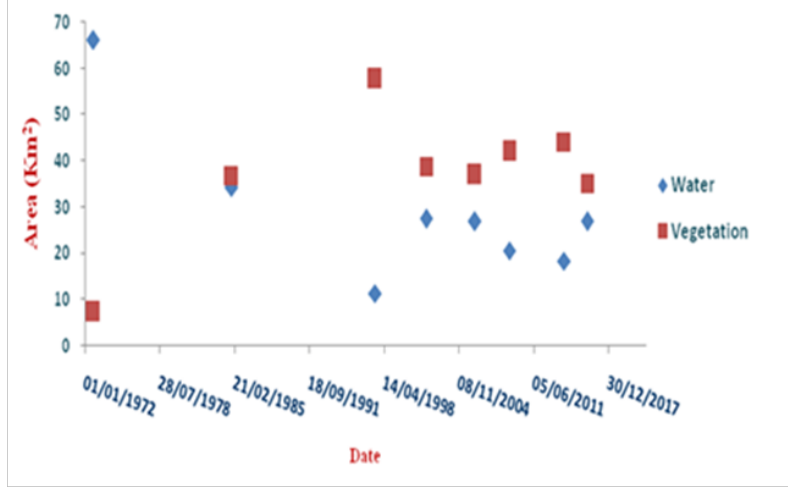

Figure 3 NDWI changes of Mariout Lake during 1972-2016.

\section{Results}

The analysis's identified the rate of environmental changes over the four decades for lake; this was undertaken using satellite images to employ historical remotely sensed data to reveal the long-term changes in the physical characteristics of the Lake as shown in Figure 2. Results revealed that the overall size of the lake decreased about $20 \%$ from 1972 until 2016. The major landfill area violations are clearly identified in Main, Northwest, and Southwest basin, so there are noticed all over the boundary of these basins. After the complete of NDWI of all satellite images from (1972-2016) as shown in Figure 3 and calculated the water and vegetation area, this process completed by converted the NDWI classification into vector layers using ENVI 5.1 software and then using ARCGIS 10.2.2 to complete the calculation of areas. The change detection was performed to calculate decrease, unchanged, and losses area during last Four decades (1972 to 2016) as shown in Figure 4. 

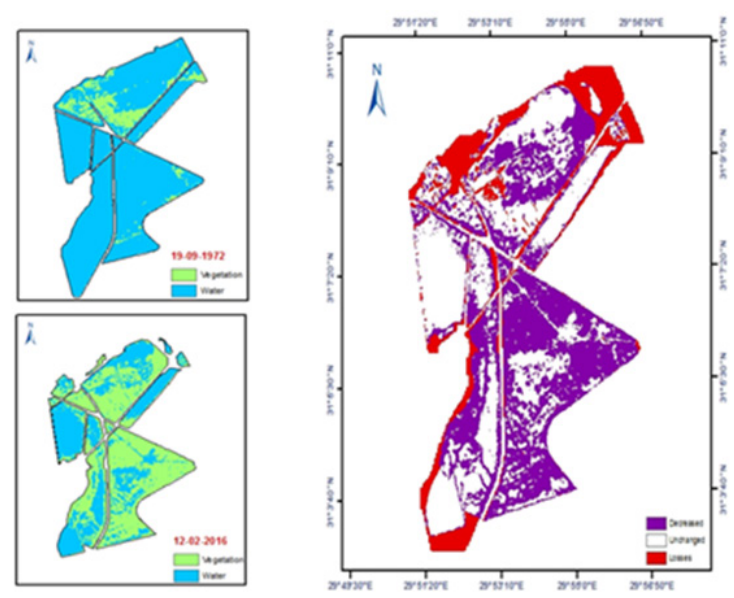

Figure 4 Change detection method: Before 1972; after 2016; Change detection map (difference image).

\section{Conclusions and recommendations}

Remote sensing proves to be very successful in monitoring the water quality, vegetation types, and ecological changes along the Mariout Lake. These results that due to human activities including the discharge of sewage and industrial waste and the impact of canal and road networks have a serious impact on the lake. Image processing techniques as enhancements were applied to help the identification and discrimination features in and around the lake. The ultimate goal of this remote sensing research is to provide resource managers with a useful tool to monitor natural resources such as Coastal Lagoons, and make better-informed decisions about their use and conservation. Remote sensing is a valuable tool for studying Water Quality of the Mariout Lake. Integrating all available data into an easily accessible data system further improves remote sensing images potential as tool for resource managers. There is a need for a thorough assessment of the present ecological conditions of Lake Mariout as a part of the nation northern wetlands. ${ }^{10-12}$

\section{The authorities affiliations must work}

1. Carrying out a comprehensive ecological survey of the Lake,

2. Preparation of an executive action plan for the protection and rehabilitation of the Lake, this should include measures to be implemented, management of implementation, required budget, time schedule, and performance measures.

\section{Acknowledgments}

None.

\section{Conflicts of interest}

The authors declare there is no conflict of interests.

\section{Funding}

None.

\section{References}

1. Donia N. Lake maryout monitoring using remote sensing. Eighteenth International after Technology Conference, IWTC. 2015;18:230-236.

2. Ahmed MH, El-Leithy BM, Donia NS, et al. Monitoring the historical changes of Lake Manzala ecosystems during the last three decades using multidate satellite images. Paper presented at the First International Conference on Environmental Change of Lakes, Lagoons and Wetlands in the Southern Mediterranean Region, Egypt: ECOLLAW; 2006.

3. Abdelmoniem M, El-Sharkawy F, Samaan A. Some chemical features of Lake Mariout. Bull Inst Oceanogr Fish Cairo. 1987;13(1):201-217.

4. Ezz A, Aziz A. Benthic fauna of Maryout Lake. Egypt: Bull Inst of Oceanogr Fish ARE; 1999:181-202.

5. Scapini F. Sustainable management of Mediterranean coastal fresh and transitional water bodies:a socio-economic and environmental analysis of changes and trends to enhance and sustain stakeholder benefits. Coastal Water Bodies Nature and Culture Conflicts in the Mediterranean; 2009:1-5.

6. Kassim TA. Forensic analysis and source partitioning of aliphatic hydrocarbon in Lake Maruit aquatic sediments. Journal of Aquatic Research. 2005;31(2):166-181.

7. McFeeters SK. The use of the Normalized Difference Water Index (NDWI) in the delineation of open water features. International Journal of Remote Sensing. 1996;17(7):1425-1432.

8. Chowdary V, Chandran RV, Neeti N, et al. Assessment of surface and sub-surface waterlogged areas in irrigation command areas of Bihar state using remote sensing and GIS. Agricultural water management. 2008;95(7):754-766.

9. Ahmed El-Zeiny, Sameh El-Kafrawy. Assessment of water pollution induced by human activities in Burullus Lake using Landsat 8 operational land imager and GIS. The Egyptian Journal of Remote Sensing and Space Sciences. 2016.

10. Hesham M El-Asmar, Mohamed E Hereher, Sameh B El-Kafrawy. Threats Facing Lagoons along the North Coast of the Nile Delta, Egypt. IJRSA. 2012;2(2):24-29.

11. Sameh B, El-Kafrawy, Ahmad Khalafallah, Mohy Omar, Mostafa MH Khalil, et al. An integrated field and remote sensing approach for water quality mapping of Lake Burullus, Egypt. International Journal Of Environmental Science And Engineering (IJESE). 2015;6:15-20.

12. US Geological Survey (USGS) and US Department of the Interior. Normalized Difference Water Index (NDWI), USA; 2016. 